\title{
Intracameral air following pneumatic noncontact tonometry in a recently post-perforating keratoplasty patient
}

This article was published in the following Dove Press journal:

Clinical Ophthalmology

15 April 2014

Number of times this article has been viewed

\section{Péter Vámosi}

Department of Ophthalmology, Péterfy Sándor Hospital, Budapest, Department of Ophthalmology, Medical and Health Science Centre, University of Debrecen, Debrecen, Hungary
Correspondence: Péter Vámosi

Department of Ophthalmology, Péterfy Sándor Hospital, Péterfy Sándor u 8-20,

Budapest, $\mathrm{H}-1$ 076, Hungary

Tel +36 302902621

Fax +36 I 46| 4790

Email vamosipeter@freemail.hu
Purpose: The purpose of this report is to highlight the potential risk of noncontact tonometry after routine uncomplicated penetrating keratoplasty (PK).

Case report: After uncomplicated PK for keratoconus, routine noncontact tonometry was performed on the second postoperative day. In spite of the adequately closed wound and the tight suture, temporary wound dehiscence occurred, and two-thirds of the anterior chamber was occupied by air. The running suture remained intact, and the Seidel test was negative. One week postoperatively, the patient's corrected distance visual acuity was 0.4 (0.4 logMAR), and the air bubble had absorbed.

Conclusion: This is the first report to conclude that noncontact tonometry may not be sufficiently safe in the early postoperative period in normal PK cases. To prevent possible wound opening, we suggest the use of other tonometry methods during the first several months after PK.

Keywords: wound dehiscence, penetrating keratoplasty

\section{Introduction}

As the noncontact tonometer (NCT) does not come into contact with the eye, possible complications associated with direct contact with the ocular surface, such as abrasion, the transmission of infectious agents, or chemical injuries, are less likely. Mainly minor complications have been reported following use of the NCT, but there have also been rare major complications, such as the opening of a corneal wound. ${ }^{1-3}$ Altogether, five cases of corneal perforations have been reported, two of them involving postkeratoplasty eyes, with different postoperative pathologies. ${ }^{2,3}$ In contrast, the case we present here occurred after a normal penetrating keratoplasty (PK) with no intraor postoperative complications. Following routine noncontact tonometry, the corneal wound temporarily opened, and two-thirds of the anterior chamber was occupied by air, but the running suture remained intact. After the absorption of the air bubble from the anterior chamber, the visual acuity improved rapidly and, other than close monitoring, the patient did not need any further intervention.

\section{Case report}

A 42-year-old man had undergone PK for keratoconus in the right eye. A $7.25 \mathrm{~mm}$ graft was sutured, with a 10-0 nylon running suture, into the $7.00 \mathrm{~mm}$ host bed. The epithelium of the graft was removed at the end of the surgery. The first postoperative day was as usual after PK; the patient had a foreign body sensation, with epiphora and photophobia. Slit lamp examination revealed a transparent graft in niveau, free of epithelium and with Descemet's striae. The wound was closed, the running suture 
seemed tight enough, and the anterior chamber was deep and clear. The visual acuity was 0.04 (1.4 $\log$ MAR) with no correction. On the second postoperative day, routine tonometry was performed, by the assistant, on the operated eye. The intraocular pressure (IOP) was measured with an NCT (CT-80 Non-Contact Computerized Tonometer; Topcon Corp, Tokyo, Japan); the automatic measurement setting was used, and the measuring range was set in the initial range: $0-30 \mathrm{mmHg}$. This instrument uses nonsterile air for the measurement. Direct contact with the eye was impossible because the triple safety function of the instrument was in operation. Immediately after the procedure, the patient felt a sharp pain, experienced a deterioration of his visual acuity, and an error signal was indicated on the display. Slit lamp examination revealed that the anterior chamber was well formed, but was two-thirds filled with air. The running suture appeared intact, and no anterior displacement of the wound or anterior wound gap could be observed. A slight stromal haze was noted in the superior part of the graft; the Seidel test was negative. ${ }^{4}$ For this reason, we decided on no intervention but simply, close observation of the patient. On the third postoperative day, the air bubble still occupied one-half of the chamber, and the eye remained sensitive. Four days after surgery, the anterior chamber was only onequarter filled with the air bubble (Figure 1), and the photophobia had improved considerably. The visual acuity was 0.1 (1.0 logMAR), with no correction. At the 1 -week control, the patient was practically free of complaints. His visual acuity was 0.25 (0.6 logMAR), improving to 0.4 (0.4 logMAR) with $\mathrm{a}+1.0$ diopter sphere, and a slit lamp biomicroscopy evaluation revealed a clear cornea with Descemet's striae, a clear anterior chamber, and a completely healed epithelium. One month

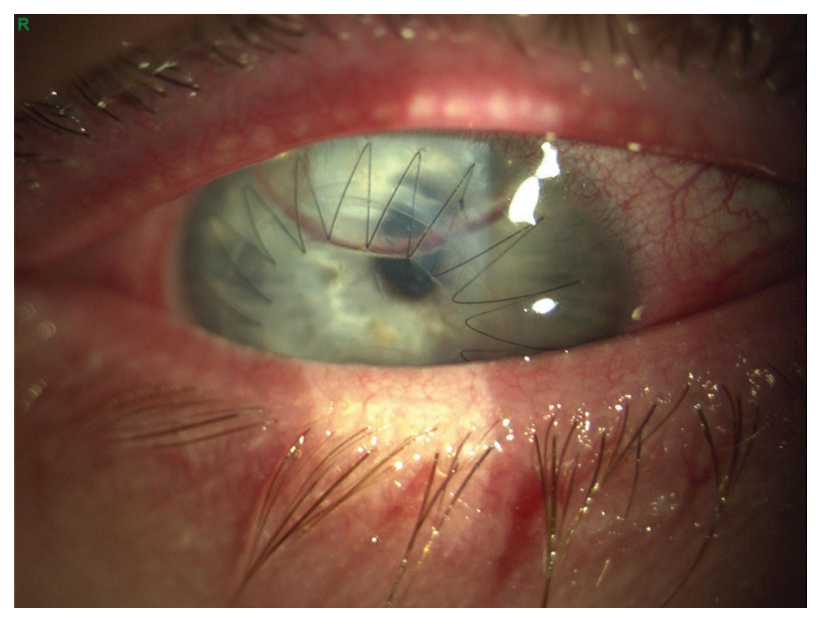

Figure I Four days after surgery and 2 days after noncontact tonometry, an air bubble occupied one-quarter of the anterior chamber. The suture remained intact, and the Seidel test was negative. postoperatively, the uncorrected distant visual acuity had gained to 1.0 (0.0 $\log \mathrm{MAR})$, the corneal astigmatism was 2.5 diopters, and the graft was clear. In the following 1 year, the status of the patient remained practically the same. He was treated with topical antibiotics (levofloxacin $0.5 \%$ ) for 1 week, and steroid (dexamethasone $0.1 \%$ ) five times a day in the first week, with the steroid drops (dexamethasone $0.1 \%$ ) tapering off during the first year.

\section{Discussion}

The NCT is based on the same principle as Goldmann applanation tonometry (GAT). The IOP is equal to the pressure needed to flatten a portion of the cornea according to the Imbert-Fick law. An air column from a pneumatic system flattens a circular area $3.0 \mathrm{~mm}$ in diameter at the center of the cornea, and a light sensor perceives the light reflected from the cornea. The time interval required for the air pulse to flatten the cornea is converted to IOP. ${ }^{5}$

The NCT is widely used for the measurement of IOP after different forms of eye surgery, including the early postoperative period. Mainly minor complications have been reported in association with noncontact tonometry, including superficial epithelial staining, patient discomfort, and microaerosol formation during the measurement. ${ }^{6-8}$ More seldom, the NCT may also cause major complications, such as posterior vitreous and retinal detachment. ${ }^{9,10}$ A survey of the literature for problems associated with the use of the NCT after PK reveals only cases where opening of the eyeball occurred at a predilection point. Kim and Kim described the perforation of a graft that was extremely thin centrally, as well as another PK case where the suture was probably loose before the measurement of the IOP. ${ }^{2}$ Katz et al reported a PK case with ongoing transplantation rejection, 18 months after the operation; they presumed that the scar at the grafthost interface was adequate. ${ }^{3}$ In my opinion, during the corneal transplantation rejection process, the wound can loosen and become a weak point. The case reported by Katz et al had an unfavorable outcome because the rejection process progressed to total graft failure. ${ }^{3}$ In our case, there was no sign of wound dehiscence, and the running suture appeared tight enough; nevertheless, wound opening took place after the use of the NCT. Although our case had a favorable outcome, such insults of the eye could possibly lead to much more severe consequences.

NCT is a fast and easy way to measure the IOP after PK, but in certain cases, it can cause wound dehiscence in the postoperative period. To prevent possible wound opening, 
we suggest the use of other tonometry methods during the first several months after PK.

\section{Disclosure}

The author reports no conflicts of interest in this work.

\section{References}

1. Porges $Y$, Ophir A. Noncontact tonometry in perforating corneal injuries. Cornea. 2000;19(3):407-409.

2. Kim EC, Kim MS. Three cases of corneal perforation caused by noncontact tonometry. Cornea. 2008;27(10):1191-1194.

3. Katz NN, Byers NT, Bergquist RJ. Inadvertent intracameral air instillation during noncontact tonometry. Am J Ophthalmol. 1983;95(5): 708-709.

4. Cain W Jr, Sinskey RM. Detection of anterior chamber leakage with Seidel's test. Arch Ophthalmol. 1981;99(11):2013.

Clinical Ophthalmology

\section{Publish your work in this journal}

Clinical Ophthalmology is an international, peer-reviewed journal covering all subspecialties within ophthalmology. Key topics include: Optometry; Visual science; Pharmacology and drug therapy in eye diseases; Basic Sciences; Primary and Secondary eye care; Patien Safety and Quality of Care Improvements. This journal is indexed on

Submit your manuscript here: http://www.dovepress.com/clinical-ophthalmology-journal
5. Rosentreter A, Neuburger M, Jordan JF, Schild AM, Dietlein TS. [Factors influencing applanation tonometry - a practical approach]. Klin Monbl Augenheilkd. 2011;228(2):109-113. German.

6. Cook JA, Botello AP, Elders A, et al; Surveillance of Ocular Hypertension Study Group. Systematic review of the agreement of tonometers with Goldmann applanation tonometry. Ophthalmology. 2012;119(8):1552-1557.

7. Myers KJ, Scott CA. The non-contact (“air puff”) tonometer: variability and corneal staining. Am J Optom Physiol Opt. 1975;52(1):36-46.

8. Britt JM, Clifton BC, Barnebey HS, Mills RP. Microaerosol formation in noncontact 'air-puff' tonometry. Arch Ophthalmol. 1991;109(2): 225-228.

9. Linder BJ. Posterior vitreous detachment: a possible complication of noncontact tonometry. Ann Ophthalmol. 1993;25(2):54-55.

10. Axer-Siegal R, Weinberger D, Weiss Y, Yassur Y. Retinal detachment after noncontact pneumatic tonometry. Retina. 1996;16(1):80-81.

PubMed Central and CAS, and is the official journal of The Society of Clinical Ophthalmology (SCO). The manuscript management system is completely online and includes a very quick and fair peer-review system, which is all easy to use. Visit http://www.dovepress.com/ testimonials.php to read real quotes from published authors. 